\title{
An alternative approach to determination of Covid-19 personal risk index by using fuzzy logic
}

\author{
Hakan Şimşek ${ }^{1}$ (i) Elifnaz Yangın ${ }^{1}$
}

Received: 25 August 2021 / Accepted: 16 November 2021 / Published online: 27 January 2022

(c) IUPESM and Springer-Verlag GmbH Germany, part of Springer Nature 2021

\begin{abstract}
COVID-19 disease is an outbreak that seriously affected the whole world, occurred in December 2019, and thus was declared a global epidemic by WHO (World Health Organization). To reduce the impact of the epidemic on humans, it is important to detect the symptoms of the disease in a timely and accurate manner. Recently, several new variants of COVID-19 have been identified in the United Kingdom (UK), South Africa, Brazil and India, and preliminary findings have been suggested that these mutations increase the transmissibility of the virus. Therefore, the aim of this study is to construct a support system based on fuzzy logic for experts to help detect of COVID-19 infection risk in a timely and accurate manner and to get a numerical output on symptoms of the virus from every person. The decision support system consists of three different sub and one main Mamdani type fuzzy inference systems (FIS). Subsystems are Common- Serious symptoms (First), Rare Symptoms (Second) and Personal Information (Third). The first FIS has five inputs, fever-time, cough-time, fatigue-time, shortness of breath and chest pain/dysfunction; the second FIS has four inputs, Loss of Taste/Smell, Body Aches, Conjuctivitis, and Nausea/Vomiting/Diarrhea; and the third FIS has three inputs, Age, Smoke, and Comorbidities. Then, we obtain personal risk index of individual by combining the outputs of these subsystems in a final FIS. The results can be used by health professionals and epidemiologists to make inferences about public health. Numerical output can also be useful for self-control of an individual.
\end{abstract}

Keywords COVID-19 $\cdot$ Risk index $\cdot$ Fuzzy inference $\cdot$ Symptoms

\section{Introduction}

COVID-19 is the disease caused by a new coronavirus called severe acute respiratory syndrome coronavirus 2 (SARSCoV-2). This new virus was emerged in Wuhan, China in December 2019 and has spread all over the World in a short time. The disease was declared a global epidemic by the World Health Organization (WHO) on March 11, 2020 due to deep concern both with alarming levels of spread and severity and alarming inertia levels, [1]. Until now, there have been approximately 241 million confirmed cases, including 4.9 million deaths, reported to WHO, [2]. According to WHO, the most common symptoms of COVID19 detected in confirmed cases are Fever, Dry cough and

This article is part of the COVID-19 Health Technology: Design, Regulation, Management, Assessment

Hakan Şimşek

hakan.simsek@antalya.edu.tr

1 Antalya Bilim Üniversitesi, Antalya, Turkey
Fatigue; serious symptoms of COVID-19 are difficulty breathing or shortness of breath, chest pain or pressure in the chest and dysdunction or confusion; and other symptoms of COVID-19 are loss of taste or smell, nasal congestion, conjunctivitis, sore throat, headache, muscle or joint pain, different types of skin rash, nausea or vomiting, diarrhea and chills or dizziness, [3]. It was determined that the symptoms and the severity of the disease differ according to age, chronic disease, immune system or genetic factors. We see the various charateristic and situation of COVID-19 from the systematic, comprehensive reviews and meta-analysis articles, [4-8]. Recently, several new variants of COVID19 have been identified in the United Kingdom (UK), South Africa, India and Brazil, and preliminary findings have been suggested that these mutations increase the transmissibility of the virus, [9-11]. The Delta variant, first reported in India, has been affecting currently in most of countries around the World, [12]. Studies on the variants of COVID19 virus have been continuing and new mutants and variants are emerging. 
The severity of COVID-19 symptoms can range from very mild to severe. Some people may have only a few symptoms, and some people may have no symptoms at all, called asymptomatic. Some people may experience worsened symptoms, such as worsened shortness of breath and pneumonia. Because some of the symptoms of flu and COVID-19 are similar, it may be hard to tell the difference between them based on verbal, ambiguous and intuitive responses. On the other hand, older people are at higher risk of serious illness from COVID-19, and the risk increases with age. People with existing medical conditions may have a higher risk of serious illness. In [13], the symptoms of 46,248 COVID-19 infected patients were examined. Chronic diseases accompanying infected patients were frequently associated with $17 \%$ hypertension, $8 \%$ diabetes, $5 \%$ cardiovascular diseases and $2 \%$ respiratory diseases. In [14], it was found that of 76.993 patients infected with COVID-19, 16.37\% had hypertension, $12.11 \%$ had cardiovascular disease, $7.63 \%$ had a history of smoking, and $7.87 \%$ had a history of diabetes. Asymptomatic or mildly symptomatic individuals are not aware of their contagion, causing them not to seek healthcare professional support and an increase in the number of infected people. At the same time, rapid detection, isolation, and contact tracing of community COVID-19 cases are essential measures to limit the community spread of COVID-19, [15].

In the medical field, many of the concepts are fuzzy, making them difficult to model and objectify. Moreover, medical diagnosis is a complex process since the associated symptoms can be complex and the vague, and indirect-unknown relationships of the symptoms with the final output is very difficult to recognize and work with, [16]. Today, medical diagnosis processes are carried out with the help of computer-related technologies based on human reasoning, which is increasing day by day. These systems are mostly based on the principles of artificial intelligence and are designed not only to make a diagnosis based on symptoms but also to prescribe treatments based on it. Fuzzy modelling is deemed to be an appropriate technique for modelling the uncertainty in the medical domain, [17]. Thus, fuzzy approach is the most suitable technique for modelling and supporting the medical diagnostic decision. On the other hand, the outputs of this approach will help both to gain awareness and to be able to separate information by synthesizing and to choose the best / right among the options. Consequently, alternative studies on smart systems that provide rapid results regarding COVID-19 symptoms are very important to help detect in time whether a person has been infected or not with the virus.

Some of the researches based on the relationship between the fuzzy approach and medical field can be seen as follows. In [18], design and development of a fuzzy rule-based expert system to identify the current stage of chronic kidney disease is proposed. The development of a medical diagnostic system using fuzzy logic is covered in [19] in order to enhance the accuracy and precision of medical diagnosis. In [20], a new Hybrid Diagnose Strategy (HDS) that consists of two classifiers; fuzzy inference engine and Deep Neural Network (DNN) is introduced for COVID-19. In the study [21], an intelligent fuzzy inference system for the primary diagnosis of COVID-19 is proposed, which infers the likelihood level of COVID-19 infection based on the symptoms. an Adaptive Neuro-Fuzzy Inference System (ANFIS) is proposed in [22] as a key rule for automatic COVID-19 detection from chest X-ray images based on the characteristics derived by texture analysis. In another similar study [23], a fuzzy rule-based inference system is presented to support medical diagnoses, to minimize health costs and to maximize health resources based on real data selected by medical groups in the health market. In [24], an intelligent medical diagnostic system to diagnose renal cancer is developed by using fuzzy and neuro-fuzzy techniques. A fuzzy model for a bone disease to have the right diagnosis answer is proposed in [25]. Based on the references of 173 articles from 124 journals, the development trend and application potential of fuzzy expert system in the medical field over the past two decades are reviewed in [26]. In [27], fuzzy inference systems to improve the quality of the day-by-day clinical care of type-2 diabetic patients of Anti-Diabetes Centre (CAD) of the Local Health Authority ASL Naples 1 are presented. Govindan et al. [28] developed a decision support system based on physicians' knowledge and fuzzy inference system (FIS) in order to help with the demand management in the healthcare supply chain and to break down the COVID-19 propagation. Mangla et al. [29] cover three important types of factors, risk factors, clinical factors, and miscellaneous factors, that influence the mortality rate of COVID-19 under the Mamdani-based fuzzy expert system. In [30], a fuzzy expert system, a clinical decision support system, is developed for diagnosis and prediction of chronic kidney disease.

There are many studies and researches on various issues related to COVID-19 in fuzzy environment. Al-Qaness et al. [31] presents a forecasting model to estimate the number of confirmed cases of COVID-19 in the upcoming ten days based on the previously confirmed cases recorded in China by using ANFIS. By using fuzzy logic, Boucenna et al. [32] dealt with the analysis of the spread of COVID-19 and the people likely to be affected. Chowdhury et al. [33] worked on the assessment of the effective role of various environmental conditions in the spread of COVID-19 with the help of the fuzzy inference system. Fu and Liang [34] analyzed household medical products using fuzzy logic for the COVID-19 anti-epidemic normalization. Gemmar [35] compared alternative and advanced model approaches with models proposed in literature in order to estimate the state of health and to predict patient mortality risk. Painuli et al. [36] tried to propose a fuzzy rule based system to give predictions 
Fig. 1 Fuzzy Inference System

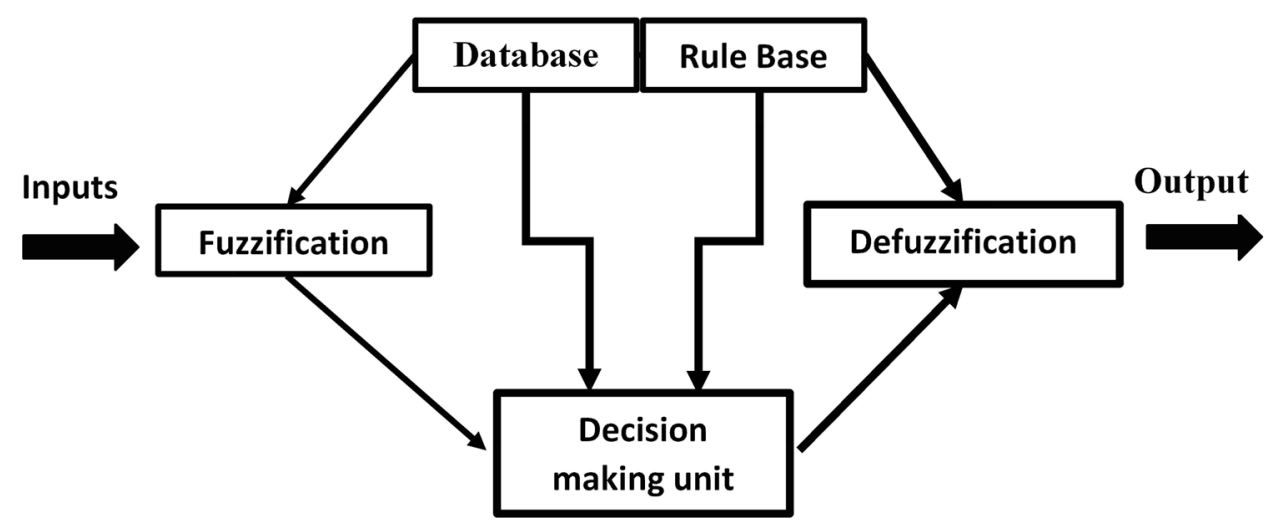

related to whether one is suffering from COVID-19 or not. Shaban et al. [37] introduced a new Hybrid Diagnose Strategy (HDS) relying on fuzzy logic and deep neural network to detect COVID-19 patients. Chowdhury et al. [38] used the Adaptive Neuro-Fuzzy Inference System (ANFIS) and the long short-term memory (LSTM) to predict the newly infected cases of COVID-19 in Bangladesh. Castillo and Melin [39] offer a hybrid intelligent approach for forecasting COVID-19 time series combining fractal theory and fuzzy logic. Ardabili et al. [40] described a comparative analysis of MLP and ANFIS models to predict the COVID-19 outbreak. Sharma et al. [41] proposed a mediative fuzzy correlation mathematical technique providing a relation between the increments of COVID-19 positive patients in terms of the incremental transition with respect to time.

The aim of this article is to construct more practical and useable Mamdani-type fuzzy inference intelligent technique for experts to help detect of COVID-19 infection risk and to get a numerical output on symptoms of the virus from every person coming testing for COVID-19. The paper is organized as follows. In Section 2, the structure of fuzzy logic inference system is explained. The proposed method is presented in Section 3. Finally, discussion and conclusion are given in Section 4.

\section{About fuzzy logic}

Fuzzy Logic provides artificial intelligence methods that resemble human reasoning for handling the various type uncertainties. Fuzzy Inference Systems produce an output by processing incomplete, ambiguous fuzzy inputs of a problem that can be defined by linguistic parameters. Fuzzy inference system consists of a fuzzification interface which transforms the crisp inputs into degrees of match with linguistic values; a rule base containing a number of fuzzy IF-THEN rules; a database defining the membership functions of the fuzzy sets used in the fuzzy rules; a decision-making unit performing the inference operations on the rules; and finally a defuzzification interface which transforms the fuzzy results of the inference into a crisp output (Fig. 1). More information about this concept can be found in the literature, [42-45].

A fuzzy set $\widetilde{A}$ in a universe of discourse $X$ is defined by a membership function

$\mu_{\widetilde{A}}: X \rightarrow[0,1]$

such that it associates a real number giving a membership degree of each element $x$ in the range $[0,1]$. Fuzzy numbers are special fuzzy sets satisfying the following conditions (Fig. 2);

- Convex fuzzy set (if $\mu_{\widetilde{A}}\left(\lambda x_{1}+(1-\lambda) x_{2}\right) \geq \mu_{\widetilde{A}}\left(x_{1}\right) \wedge \mu_{\widetilde{A}}\left(x_{2}\right)$ for all $\lambda \in(0,1]$ and $x_{1}, x_{2} \in X$, then $A$ is a convex fuzzy set.),

- Normalized fuzzy set (if $\operatorname{Core}(\widetilde{A})=\left\{x \in X: \mu_{\widetilde{A}}(x)=\right.$ $1\} \neq \varnothing$, then $\widetilde{A}$ is normalized.),

- It's membership function is piecewise continuous,

- It is defined in the real number.

There are different classes of fuzzy numbers suh as Triangular, Trapezoidal, Gaussian, S-shaped, G-bell, Z-shaped, Sigmoidal fuzzy numbers, which appear in real-world

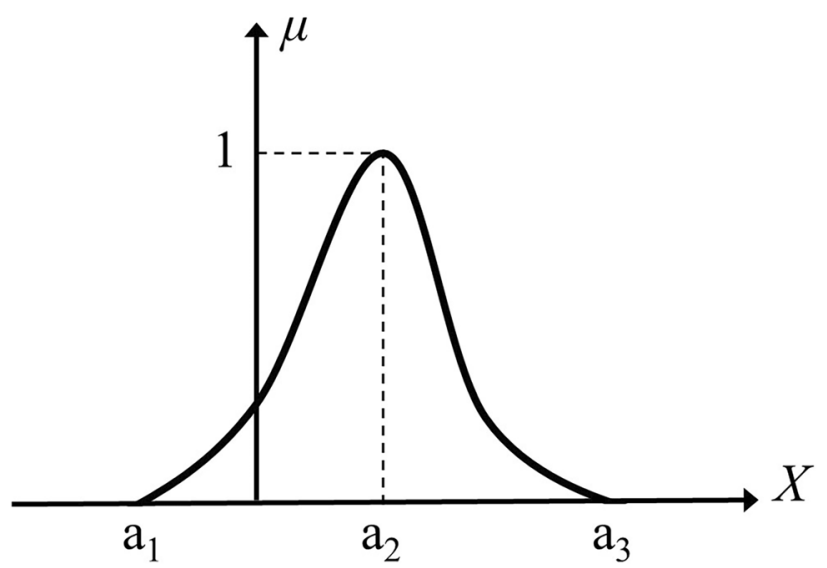

Fig. 2 Fuzzy number 
problems. Fuzzy numbers are used in fuzzification interface of an inference system; namely, inputs are described by fuzzy numbers in the system.

A fuzzy rule base consist of a set of fuzzy IF-THEN rules, which are the main theme of the FIS. All other components such as membership functions are used to implement these rules in a reasonable, realistic and efficient manner. A fuzzy IF-THEN rule generally assumes the form

$\mathbf{R}:$ If $\mathbf{x}_{1}$ is $\widetilde{A}_{1} \operatorname{AND}(\mathrm{OR}) \mathbf{x}_{2}$ is $\widetilde{A}_{2}$, THEN $\mathbf{y}$ is $\widetilde{B}$,

where, $\widetilde{A}_{1}, \widetilde{A}_{2}$ and $\widetilde{B}$ are linguistic variables of the FIS defined by fuzzy numbers on input and output universes, respectively. Logical operators AND, OR are known as the fuzzy intersection or conjuction (AND), and fuzzy union or disjunction (OR), respectively and defined as follows:

$$
\begin{array}{r}
\widetilde{A}_{1} \operatorname{AND} \widetilde{A}_{2}: \min \left\{\mu_{\widetilde{A_{1}}}, \mu_{\widetilde{A_{2}}}\right\}, \\
\widetilde{A}_{1} \text { OR } \widetilde{A}_{2}: \max \left\{\mu_{\widetilde{A_{1}}}, \mu_{\widetilde{A_{2}}}\right\} .
\end{array}
$$

After determining the rule base, we apply the process by which the fuzzy sets that represent the outputs of each rule are combined into a single fuzzy number (set), which is known as aggregation of rules. Aggregation could be done by different operators, such as Max, Sum or Probor. The Max operator is generally preferred when compensation between input variables is desirable. The Max operator is given by:

$\mu_{\text {output }}=\max \left\{\mu_{\text {rule }^{1}}, \mu_{\text {rule }} e^{2}, \ldots, \mu_{\text {rule }}\right\}$.

The last step is the defuzzification interface such that output fuzzy set obtained after the aggregation step is changed to a crisp number. Defuzzification techniques used in Mamdani based fuzzy inference system are generally Center of area or centroid (CoA), Bisector of area, Small of maxima (SoM), Mean of maxima (MoM), and Largest of maxima (LoM). The Mean of maxima (Fig. 3) gives a defuzzified crisp value $x^{*}$ as the element with the highest membership values such that the mean value of the maxima is taken when there are more than one element having maximum membership values.

All these mathematial operations explained above can be done using the MATLAB Fuzzy Logic Toolbox. In this paper, Mamdani type fuzzy inference system is used for the personal risk index of COVID-19, which is the most common in practice and in the literature. We apply max-min inference method for composition and minimum operator for implication. Gaussian Fuzzy numbers whose membership function is defined in (1) are used generally for the inputs and the aggregation is determined as the Max operator. As the defuzzifiation method, the Mean of maxima is taken for the proposed Mamdani type Fuzzy Inference Systems discussed below.

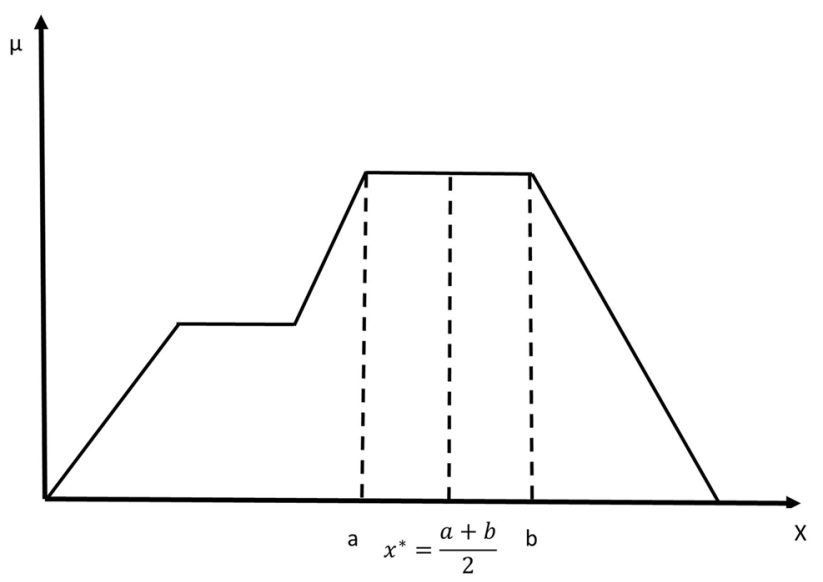

Fig. 3 The mean of maxima defuzzification

$f(x ; \sigma, c)=\exp \left(\frac{-(x-c)^{2}}{2 \sigma^{2}}\right)$,

where $c$ and $\sigma$ are the parameters of the Gaussian fuzzy number, which determine the membership ship center (the peak of the curve) and the membership function width, respectively.

\section{Proposed fuzzy inference system}

COVID-19 is a contagious pandemic with an estimated reproduction number of 2.87, [46], and thus is spreading over multiple countries or continents. In order to know whether or not you have the virus, two types of tests are applied: molecular tests (also called PCR tests, viral RNA tests, nucleic acid tests) and antigen testing, [47, 48]. The decision on whether to test for COVID-19 can be made based on the individual applicant's verbal expression of whether he/she has symptoms of the virus and how severe the symptoms are. Therefore, an inference system bringing out appropriate human reasoning capabilities can be developed in order to support the decision of whether to test or not, in order to further clarify the virus symptoms of the person, in order to make them numerical data and to obtain comparative results, and in order to better manage growing demand and make quick decisions. In this paper, we construct such a system based on the FIS, expert knowledge, related literature and last information from WHO for describing a personal risk index of COVID-19 pandemic. The recommended system consists of three sub-fuzzy inference systems and a final system (Fig. 4):

- The First FIS: Common and Serious Symptoms,

- The Second FIS: Rare Symptoms,

- The Third FIS: Personal Information. 
Fig. 4 Structure of Proposed System

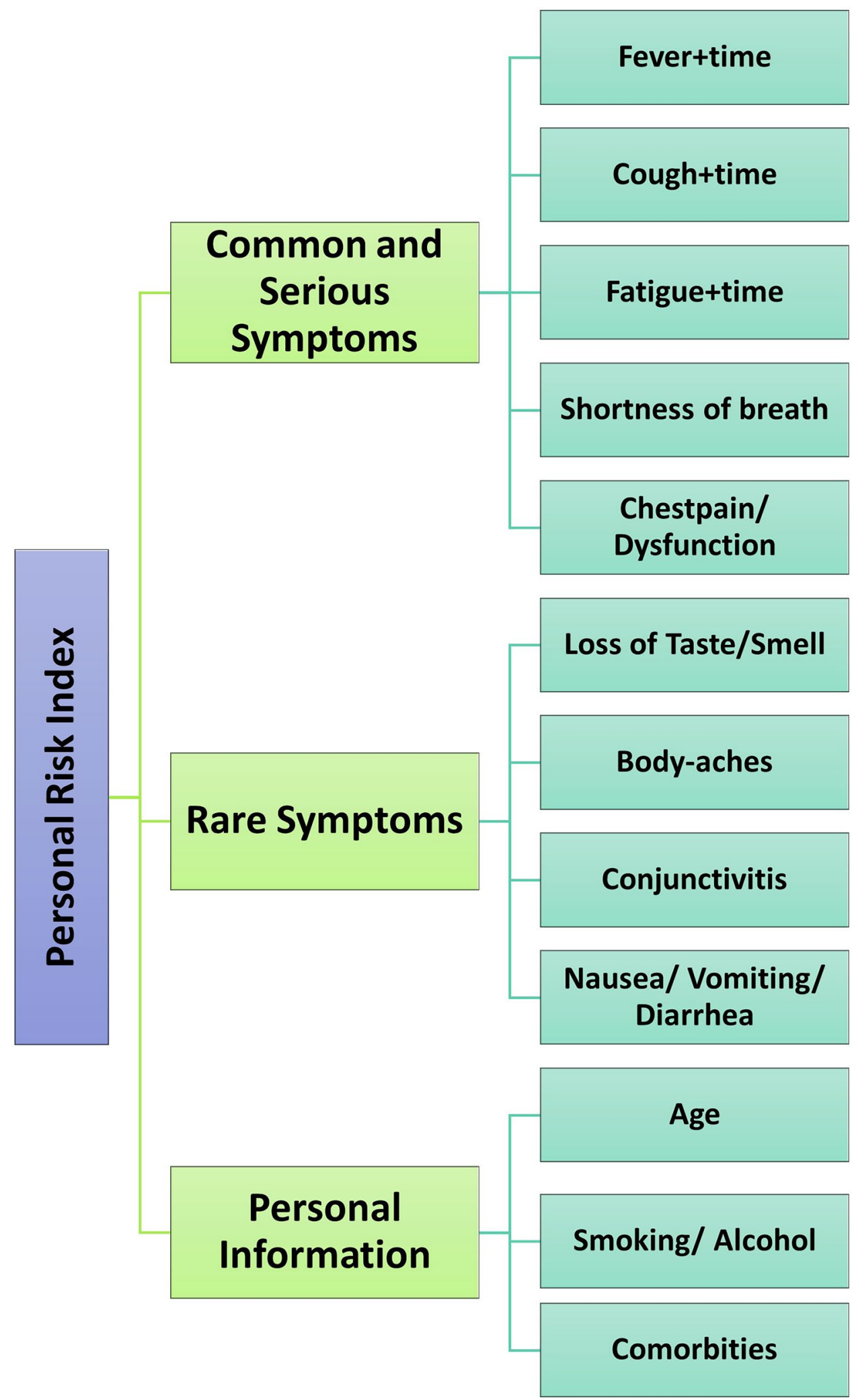

Moreover, the First FIS has three sub-fuzzy inference systems, which are the Fever-Time, Cough-Time and FatigueTime Mamdani-type inference systems. The first system provides an inference on common and serious symptoms, the second gives an output on rare symptoms, and finally the third fuzzy inference system is built in which personal 
Table 1 Fuzzy Classification of Input and Output Variables for Common and Serious Symptoms

\begin{tabular}{|c|c|c|c|c|}
\hline \multirow[t]{2}{*}{-} & \multirow[t]{2}{*}{ Linguistic Variables } & \multicolumn{3}{|c|}{ Fuzzy Membership Functions } \\
\hline & & Mild & Moderate & Severe \\
\hline \multirow[t]{3}{*}{ Input-1 } & Fever-Time & Gauss2mf & Gaussmf & S-shapedmf \\
\hline & Range: [0 10] & {$\left[\begin{array}{llll}1 & 0 & 1 & 1\end{array}\right]$} & {$\left[\begin{array}{ll}1 & 4.5\end{array}\right]$} & {$\left[\begin{array}{ll}4.5 & 8.5\end{array}\right]$} \\
\hline & & Mild & Moderate & Severe \\
\hline \multirow[t]{3}{*}{ Input-2 } & Cough-Time & Gauss2mf & Gaussmf & S-shapedmf \\
\hline & Range: $\left[\begin{array}{ll}0 & 10\end{array}\right]$ & {$\left[\begin{array}{llll}1 & 0 & 1 & 1\end{array}\right]$} & {$\left[\begin{array}{ll}1 & 4.5\end{array}\right]$} & {$\left[\begin{array}{ll}4.5 & 8.5\end{array}\right]$} \\
\hline & & Mild & Moderate & Severe \\
\hline \multirow[t]{3}{*}{ Input-3 } & Fatigue-Time & Gauss2mf & Gaussmf & S-shapedmf \\
\hline & Range: [ $\left[\begin{array}{ll}0 & 10\end{array}\right]$ & {$\left[\begin{array}{llll}1 & 0 & 1 & 1\end{array}\right]$} & {$\left[\begin{array}{ll}1 & 4.5\end{array}\right]$} & {$\left[\begin{array}{ll}4.5 & 8.5\end{array}\right]$} \\
\hline & & Mild & Moderate & Severe \\
\hline \multirow[t]{2}{*}{ Input-4 } & Shortness of Breath & Gauss2mf & Gaussmf & S-shapedmf \\
\hline & Range: [0 10] & {$\left[\begin{array}{llll}1 & 0 & 1 & 1\end{array}\right]$} & {$\left[\begin{array}{ll}1 & 4.5\end{array}\right]$} & {$\left[\begin{array}{ll}5 & 8.2\end{array}\right]$} \\
\hline \multirow[t]{3}{*}{ Input-5 } & Chestpain/ Dysfuntion & No & Yes & - \\
\hline & Range: $\{0,1\}$ & 0 & 1 & - \\
\hline & & Mild & Moderate & Severe \\
\hline \multirow[t]{2}{*}{ Output } & Risk Val. of Com.-Ser. Symp. & Gauss2mf & Gaussmf & S-shapedmf \\
\hline & & {$\left[\begin{array}{llll}1 & 0 & 1 & 1\end{array}\right]$} & {$\left[\begin{array}{ll}1.5 & 4.5\end{array}\right]$} & {$\left[\begin{array}{ll}4.5 & 8.5\end{array}\right]$} \\
\hline
\end{tabular}

information is collected. The Fever-Time, Cough-Time and Fatigue-Time FISs are formed to evaluate the relationship between the common symptoms and time. The inputs in the first and second fuzzy inference systems were created by evaluating the symptoms announced by WHO, [3]. The inputs in the third fuzzy inference system were determined as age, chronic disease and smoking-alcohol habits that affect the risk of COVID-19 disease transmission. The COVID-19 personal risk index is obtained by transforming the outputs of these sub-fuzzy inference systems into a single output in a final fuzzy inference system.

\subsection{The first FIS: common and serious symptoms}

In this FIS, we aim to get a numerical output for the common and serious symptoms of COVID-19. There are five inputs in the system; fever-time, cough-time, fatigue-time, shortness of breath and chest pain/dysfunction. The structure of the First FIS is shown in Fig. 5. Three membership functions are used for explaning linguistic variables of inputs-outputs. Paek et al. [49] formed a review study for better understanding of fatigue and also gave significant detection methods and systematic approaches to figure out the impacts and causes of fatigue such that it is explained that Karolinska sleepiness scale (KSS), a nine-point scale, has a different measure of fatigue for each point and is the most frequently used drowsiness and fatigue scale. In other study, [50], subjective and objective tests to evaluate the sense of smell, whih are commonly used in patients, were discussed like Visual Analogue Scale (VAS, 0-10 scale). On the other hand, Fontana and Widdicombe [51] investigated how to measure the cough intensity or frequency and concluded that there are many methods for measuring and assessing cough such that the choice of them, apart from practical and financial considerations, must depend on the question being asked. Therefore, we aim to collect data on the severity of pain by scoring the severity of pain in the range of $0-10$, which is also called a Likert scale. The Table 1 gives the information about the linguistic variables and fuzzy membership functions of Common and Serious Symptoms. 17 rules, several of which are given in Table 2, are formed in total for the first FIS. The mean of maxima (MoM) is chosen as the defuzzification method. The Figs. 6 and 7 show the impact of the symptoms on personal risk evaluation in 3D form as a rule surface performed in MATLAB on Cough-time and Fever-time; Shortness of Breath and Chasepain/Dysfunction, respectively.

For the fever, cough and fatigue, which are common symptoms, three separate corresponding sub-fuzzy inference systems were formed to include in the system how long a person

Table 2 A Few Rules for the first FIS: Common and Serious Symptoms

\begin{tabular}{|c|c|c|c|c|c|}
\hline \multicolumn{5}{|l|}{ Inputs } & \multirow{2}{*}{$\begin{array}{l}\text { Output } \\
\text { Risk } \\
\text { Value }\end{array}$} \\
\hline Fever-T & Cough-T & Fatigue-T & $\begin{array}{l}\text { S. of } \\
\text { Breath }\end{array}$ & $\begin{array}{l}\text { Chestpain/ } \\
\text { Dysfunc. }\end{array}$ & \\
\hline Mild & Mild & Mild & Mild & No & Mild \\
\hline Moderate & Moderate & Mild & Mild & No & Moderate \\
\hline Mild & Moderate & Moderate & Mild & No & Moderate \\
\hline$\vdots$ & $\vdots$ & $\vdots$ & $\vdots$ & $\vdots$ & $\vdots$ \\
\hline Severe & Severe & Severe & Mild & No & Severe \\
\hline Severe & Severe & Severe & Severe & Yes & Severe \\
\hline
\end{tabular}


Fig. 5 Diagram of the First FIS

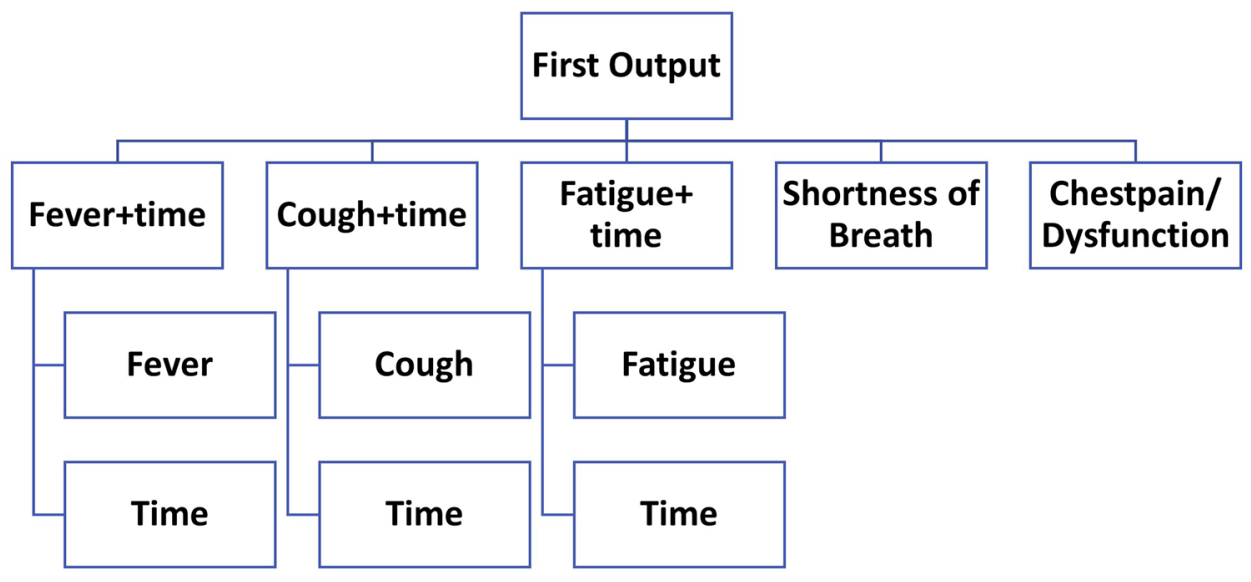

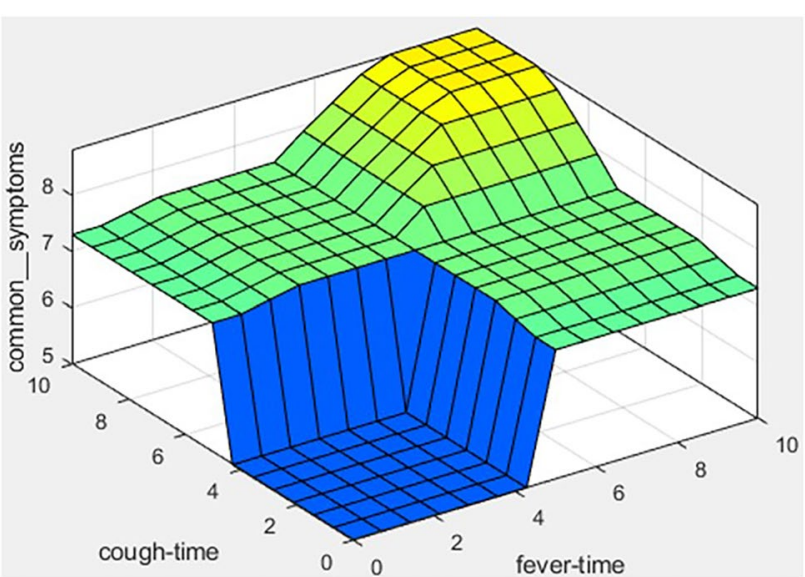

Fig. 6 Surface View of the Rule Base of the Common Symptoms (Fever-time and Cough-time)

has had these symptoms. Linguistic variables and fuzzy membership functions of fever-time gathered in Table 3 . Table 4 has some rules about fever-time sub-fuzzy inference system. There are 8 rules for this sub-fuzzy inference system and the defuzzification method is the mean of maximum. The surface view of the rule base of the fever-time is given in Fig. 8. Similar sub-FIS can be formed for the cough-time and

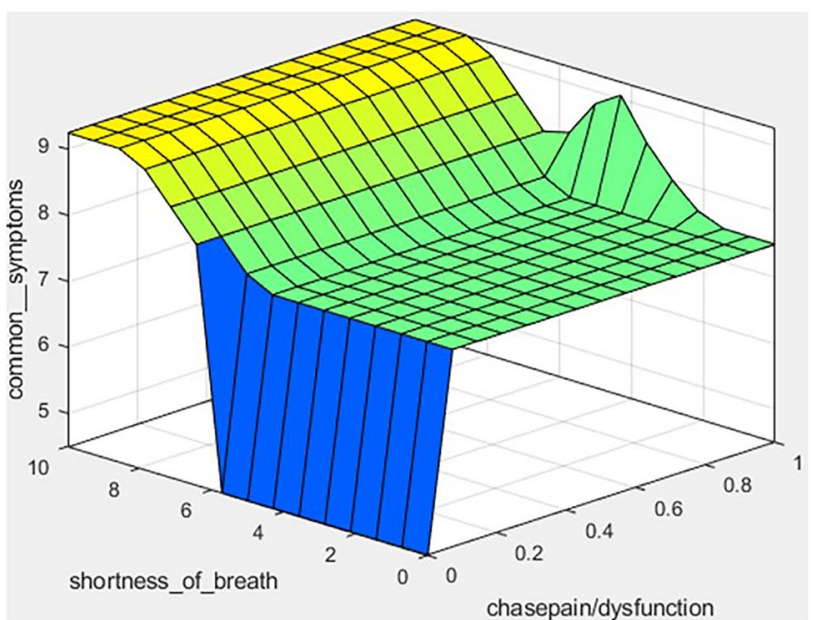

Fig. 7 Surface View of the Rule Base of the Serious Symptoms (Shortness of Breath and Chasepain/Dysfunction)

fatigue-time, which surface views of the rule base for them are shown in Figs. 9 and 10. As a result, we get the outputs for common symptoms: fever, cough and fatigue, by using the sub-fuzzy inference systems and then we reach the risk index for the common and serious symptoms by using the first FIS.
Table 3 Fuzzy Classification of Input and Output Variables for fever-time

\begin{tabular}{|c|c|c|c|c|}
\hline \multirow[t]{2}{*}{ - } & \multirow[t]{2}{*}{ Linguistic Variables } & \multicolumn{3}{|c|}{ Fuzzy Membership Functions } \\
\hline & & Mild & Moderate & Severe \\
\hline \multirow[t]{3}{*}{ Input-1 } & Fever $\left({ }^{0} C\right)$ & Gauss $2 \mathrm{mf}$ & Gaussmf & S-shapedmf \\
\hline & Range: [36 40] & {$\left[\begin{array}{llllll}0.1 & 36 & 0.4 & 36.6\end{array}\right]$} & {$\left[\begin{array}{ll}0.33 & 37.7\end{array}\right]$} & {$\left[\begin{array}{ll}37.7 & 38.7\end{array}\right]$} \\
\hline & & Beginning & Middle & High \\
\hline \multirow[t]{3}{*}{ Input-2 } & Time (Hour) & Z-shapedmf & Gaussmf & S-shapedmf \\
\hline & Range: [0 36] & {$\left[\begin{array}{ll}3 & 12\end{array}\right]$} & {$\left[\begin{array}{ll}4.5 & 16\end{array}\right]$} & {$\left[\begin{array}{ll}16 & 30\end{array}\right]$} \\
\hline & & Mild & Moderate & Severe \\
\hline \multirow[t]{2}{*}{ Output } & Fever-Time & Gauss $2 \mathrm{mf}$ & Gaussmf & S-shapedmf \\
\hline & Range: [0 10] & {$\left[\begin{array}{llll}1 & 0 & 1 & 1\end{array}\right]$} & {$\left[\begin{array}{ll}1 & 4.5\end{array}\right]$} & {$\left[\begin{array}{ll}4.5 & 8.5\end{array}\right]$} \\
\hline
\end{tabular}


Table 4 A Few Rules for Fever-time

\begin{tabular}{lll}
\hline Inputs & & Output \\
\hline Fever & Time & Fever-Time \\
\hline Mild & Beginning & Mild \\
Moderate & Middle & Moderate \\
$\vdots$ & $\vdots$ & $\vdots$ \\
Severe & High & Severe \\
\hline
\end{tabular}

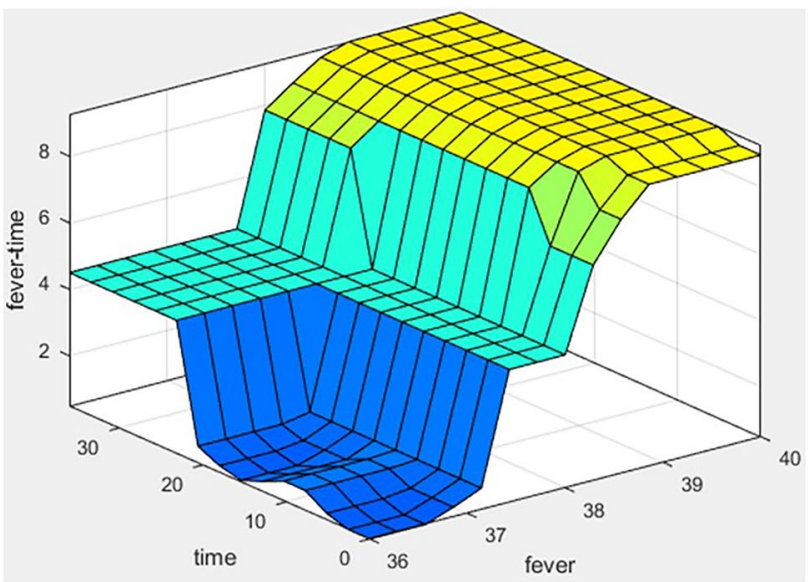

Fig. 8 Surface View of the Rule Base of the Fever-time

\subsection{The second FIS: other symptoms that are less common}

In this FIS, we aim to get a numerical output for the rare symptoms of COVID-19. There are four inputs in the system; Loss of Taste/Smell, Body Aches, Conjuctivitis, and Nausea/Vomiting/Diarrhea. The Table 6 explains the linguistic variables of inputs-output and the corresponding membership functions of the fuzzy inference system. In total, 32 rules are formed for the rare symptoms, several of which are given in Table 5. The mean of maximum (MOM) is chosen as the defuzzification method. Figs. 11 and 12 show the impact of the symptoms on risk evaluation in 3D form as a rule surface performed in MATLAB.

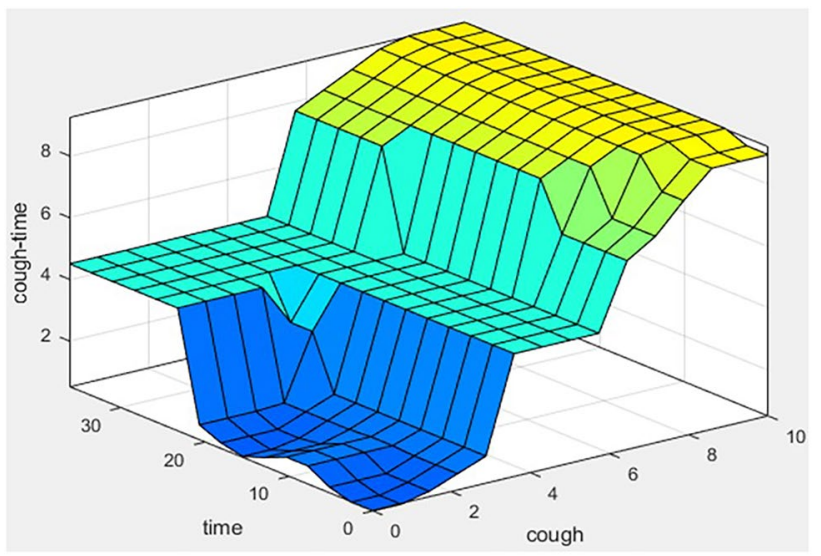

Fig. 9 Surface View of the Rule Base of the Cough-time

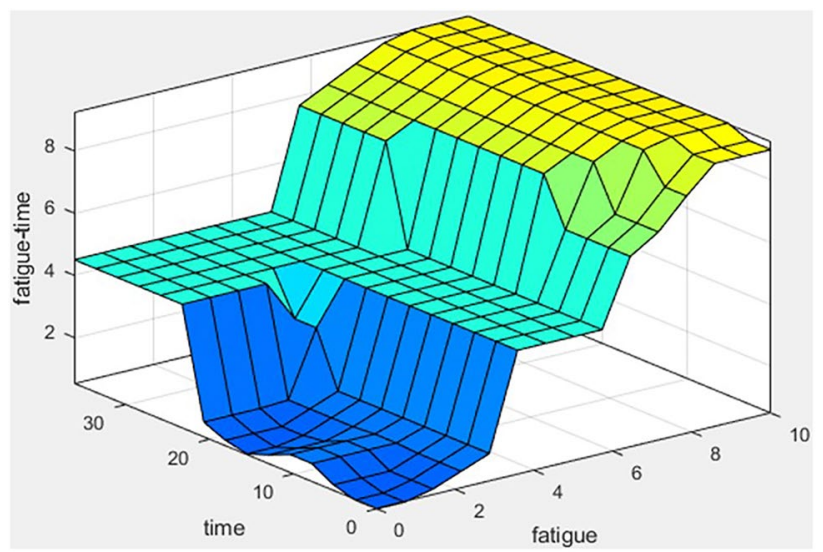

Fig. 10 Surface View of the Rule Base of the Fatigue-time

\subsection{The third FIS: personal information}

In this FIS, we aim to get a numerical output for the personal information affecting the risk value of COVID-19. There are three inputs in the system; Age, Smoke, and Comorbidities. The Table 7 explains the linguistic variables of inputs-output and the corresponding membership functions of the fuzzy
Table 5 A Few Rules for the second FIS: Rare Symptoms

\begin{tabular}{lllll}
\hline Inputs & & & & Output \\
\hline Loss of Taste/Smell & Body-Aches & Conjuctivitis & $\begin{array}{c}\text { Nause/Vomitting/ } \\
\text { Diarrhea }\end{array}$ & Risk Value \\
Mild & Moderate & Yes & No & Moderate \\
Mild & Severe & No & Yes & Severe \\
Moderate & Moderate & No & Yes & Severe \\
$\vdots$ & $\vdots$ & $\vdots$ & $\vdots$ & $\vdots$ \\
Moderate & Severe & No & Yes & Severe \\
Severe & Mild & No & No & Severe \\
\hline
\end{tabular}


Table 6 Fuzzy Classification of Input and Output Variables for Rare Symptoms

\begin{tabular}{|c|c|c|c|c|}
\hline \multirow[t]{2}{*}{-} & \multirow[t]{2}{*}{ Linguistic Variables } & \multicolumn{3}{|c|}{ Fuzzy Membership Functions } \\
\hline & & Mild & Moderate & Severe \\
\hline \multirow[t]{3}{*}{ Input-1 } & Loss of Taste/Smell & Gauss $2 \mathrm{mf}$ & Gaussmf & S-shapedmf \\
\hline & Range: $\left[\begin{array}{ll}0 & 10\end{array}\right]$ & {$\left[\begin{array}{llll}1 & 0 & 1 & 1\end{array}\right]$} & {$\left[\begin{array}{ll}1 & 4.5\end{array}\right]$} & {$\left[\begin{array}{ll}4.5 & 8.5\end{array}\right]$} \\
\hline & & Mild & Moderate & Severe \\
\hline \multirow[t]{2}{*}{ Input-2 } & Body-Aches & Gauss $2 \mathrm{mf}$ & Gaussmf & S-shapedmf \\
\hline & Range: $\left[\begin{array}{ll}0 & 10\end{array}\right]$ & {$\left[\begin{array}{llll}1 & 0 & 1 & 1\end{array}\right]$} & {$\left[\begin{array}{ll}1 & 4.5\end{array}\right]$} & {$\left[\begin{array}{ll}4.5 & 8.5\end{array}\right]$} \\
\hline \multirow[t]{2}{*}{ Input-3 } & Conjuctivitis & No & Yes & - \\
\hline & Range: $\{0,1\}$ & 0 & 1 & - \\
\hline \multirow[t]{3}{*}{ Input-4 } & Nause/Vomitting/Diarrhea & No & Yes & - \\
\hline & Range: $\{0,1\}$ & 0 & 1 & - \\
\hline & & Mild & Moderate & Severe \\
\hline Output & Risk Value of Rare Symp. & Gbellmf & Gaussmf & Gbellmf \\
\hline
\end{tabular}

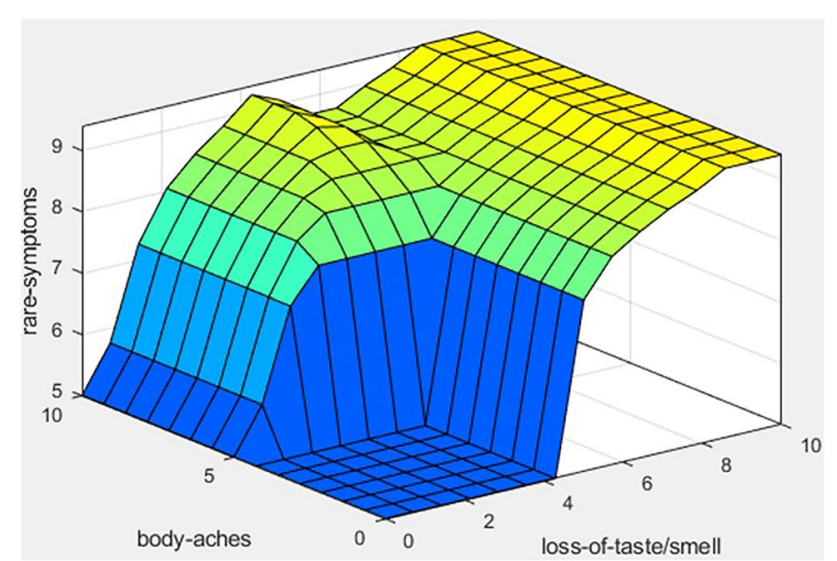

Fig. 11 Surface View of the Rule Base of Rare Symptoms (Loss of Taste/Smell and Body-Aches)

inference system. In total, 13 rules are formed for the personal information, several of which are given in Table 8. The mean of maximum (MOM) is chosen as the defuzzification method. Figure 13 illustrates the impact of the symptoms on risk evaluation in 3D form as a rule surface performed in MATLAB.

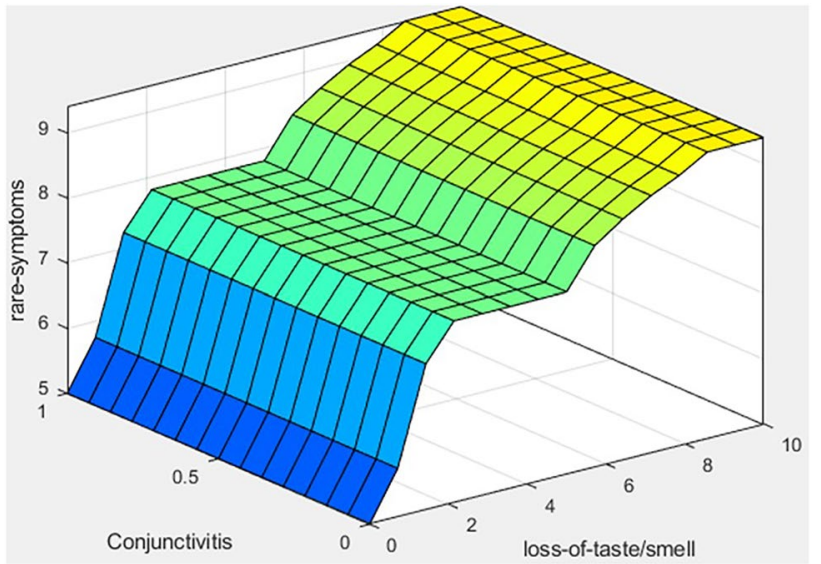

Fig. 12 Surface View of the Rule Base of Rare Symptoms (Loss of Taste/Smell and Conjuctivitis)

\subsection{Personal risk index of COVID-19}

Now, we can obtain the COVID-19 personal risk value by combining the fuzzy inference systems explained above. We present a final fuzzy inference system whose inputs are the
Table 7 Fuzzy Classification of Input and Output Variables for Personal Information

\begin{tabular}{|c|c|c|c|c|}
\hline \multirow[t]{2}{*}{-} & \multirow[t]{2}{*}{ Linguistic Variables } & \multicolumn{3}{|c|}{ Fuzzy Membership Functions } \\
\hline & & Young & Middle-Age & Old \\
\hline \multirow[t]{2}{*}{ Input-1 } & Age & Gaussmf & Gaussmf & S-shapedmf \\
\hline & Range: [18 80] & {$\left[\begin{array}{ll}5 & 18\end{array}\right]$} & {$\left[\begin{array}{ll}5.4 & 40\end{array}\right]$} & {$\left[\begin{array}{ll}35 & 65\end{array}\right]$} \\
\hline \multirow[t]{2}{*}{ Input-2 } & Smoke & No & Yes & - \\
\hline & Range: $\{0,1\}$ & 0 & 1 & - \\
\hline \multirow[t]{3}{*}{ Input-3 } & Comorbities & None & One & More than one \\
\hline & Range: $\{0,0.5,1\}$ & 0 & 0.5 & 1 \\
\hline & & Mild & Moderate & Severe \\
\hline \multirow[t]{2}{*}{ Output } & Risk Value of Personal Info & Gaussmf & Gaussmf & Gbellmf \\
\hline & & {$\left[\begin{array}{ll}1.5 & 0\end{array}\right]$} & {$\left[\begin{array}{ll}1.2 & 4.5\end{array}\right]$} & {$\left[\begin{array}{lll}3 & 2.5 & 10\end{array}\right]$} \\
\hline
\end{tabular}


Table 8 A Few Rules for the third FIS: Personal Information

\begin{tabular}{llll}
\hline Inputs & & & Output \\
\hline Age & Smoke & Comorbidities & Risk Value \\
\hline Young & Yes & More than one & Severe \\
Middle-age & No & One & Moderate \\
Old & No & One & Severe \\
$\vdots$ & $\vdots$ & $\vdots$ & $\vdots$ \\
Old & No & No & Severe \\
\hline
\end{tabular}

outputs obtained by the first, second and third fuzzy inference systems. There are 16 rules and the mean of maximum (MOM) is chosen as the defuzzification method. The Table 9, Figs. 14, 15, and 16 give the structure of the final system like the previous ones.

Then, we can discuss the performance of the proposed approach. The following questions can be asked to the person to determine the input values of the FISs in the proposed system.

- How many hours do you have a fever? (The temperature is determined by a medical thermometer)

- How many hours do you have a dry cough? And can you determine the cough severity with a decimal number between $0-10$ ?

- How many hours do you have a fatigue? And can you determine the fatigue severity with a decimal number between 0-10?

- Can you determine the severity of shortness of breath with a decimal number between $0-10$ if exist?

- Do you have a chest pain or dysfunction?

- Do you have a loss of Taste/Smell? If you have, can you determine the severity of loss of taste/smell with a decimal number between $0-10$ ?

- Do you have Body-aches? If you have, can you determine the body ache severity with a number between 1-10?

- Do you have a Conjuctivitis?

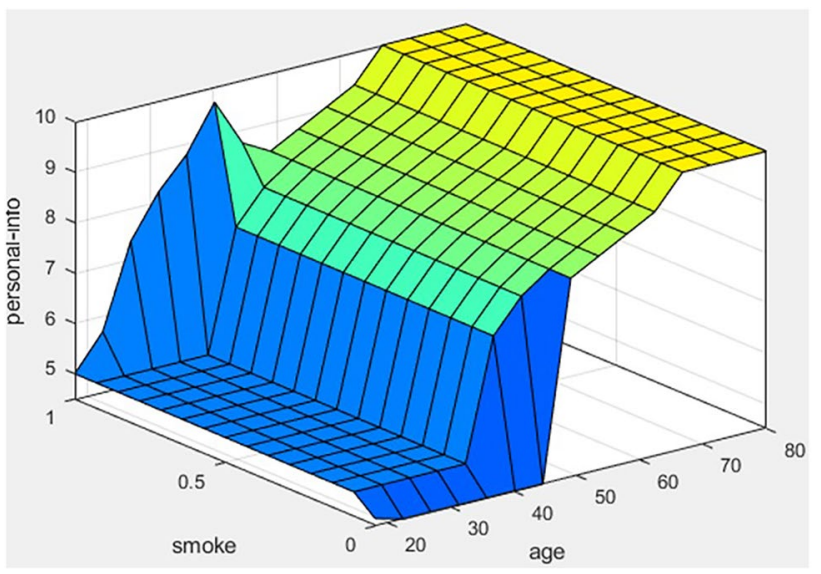

Fig. 13 Surface View of the Rule Base of the Personal Info (Age and Smoke)

- Do you have a Nausea or Vomiting or Diarrhea?

- How old are you?

- Do you use cigarettes or alcohol?

- Do you have any chronic diseases?

According to the input values obtained by the responses for these questions, we compute the outputs of the fuzzy inference systems and using the final inference system explained above, we get the final output that is the personal risk value for COVID-19 disease. The input values can be obtained by a person coming for testing, practically. Or, input information for helping the medical diagnosis can also be obtained by the patient's practical and quick response to the questions given above under the control of a physician in a digital environment. For example, the answers given by two people to the above questions may be as in Table 10 .

The outputs for the input values of the Table 10 are presented in the Table 11.
Table 9 Fuzzy Classification of Input and Output Variables for Risk Index of COVID-19

\begin{tabular}{|c|c|c|c|c|}
\hline \multirow[t]{2}{*}{ - } & \multirow[t]{2}{*}{ Linguistic Variables } & \multicolumn{3}{|c|}{ Fuzzy Membership Functions } \\
\hline & & Mild & Moderate & Severe \\
\hline Input-1 & $\begin{array}{l}\text { Com. and Ser. Symp. } \\
\text { Range: }\left[\begin{array}{ll}0 & 10\end{array}\right]\end{array}$ & $\begin{array}{l}\text { Gauss } 2 \mathrm{mf} \\
{\left[\begin{array}{llll}1 & 0 & 1 & 1\end{array}\right]}\end{array}$ & $\begin{array}{l}\text { Gaussmf } \\
{[1.54 .5]}\end{array}$ & $\begin{array}{l}\text { S-shapedmf } \\
{[4.58 .5]}\end{array}$ \\
\hline & & Mild & Moderate & Severe \\
\hline Input-2 & $\begin{array}{l}\text { Rare Symp. } \\
\text { Range: [0 10] }\end{array}$ & $\begin{array}{l}\text { Gbellmf } \\
{\left[\begin{array}{lll}1.7 & 2 & 0.1\end{array}\right]}\end{array}$ & $\begin{array}{l}\text { Gaussmf } \\
{[0.95]}\end{array}$ & $\begin{array}{l}\text { Gbellmf } \\
{\left[\begin{array}{lll}2 & 2.6 & 9.4\end{array}\right]}\end{array}$ \\
\hline & & Mild & Moderate & Severe \\
\hline Input-3 & $\begin{array}{l}\text { Personal Info } \\
\left.\text { Range: [ } \begin{array}{ll}0 & 10\end{array}\right]\end{array}$ & $\begin{array}{l}\text { Gaussmf } \\
{\left[\begin{array}{ll}1.2 & 0.01\end{array}\right]}\end{array}$ & $\begin{array}{l}\text { Gaussmf } \\
{\left[\begin{array}{ll}1.1 & 4.5\end{array}\right]}\end{array}$ & $\begin{array}{l}\text { Gbellmf } \\
{\left[\begin{array}{lll}3 & 2.5 & 10\end{array}\right]}\end{array}$ \\
\hline & & Mild & Moderate & Severe \\
\hline Final Output & $\begin{array}{l}\text { Personal Risk Value } \\
\text { Range: }\left[\begin{array}{ll}0 & 10\end{array}\right]\end{array}$ & $\begin{array}{l}\text { Gaussmf } \\
{\left[\begin{array}{ll}1.5 & 0.1\end{array}\right]}\end{array}$ & $\begin{array}{l}\text { Gaussmf } \\
{\left[\begin{array}{ll}1.1 & 4.5\end{array}\right]}\end{array}$ & 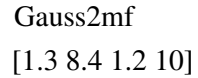 \\
\hline
\end{tabular}




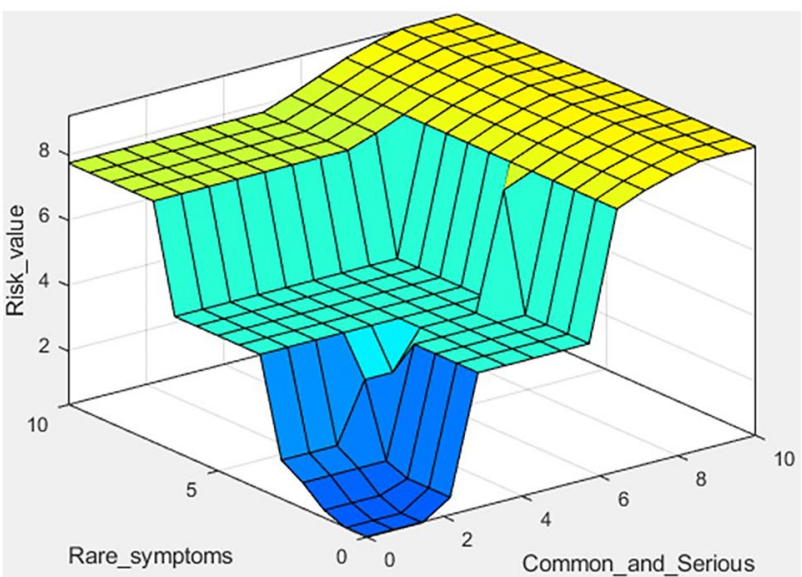

Fig. 14 Rule Base of the Risk Index (Common,-Serious and Rare Symptoms)

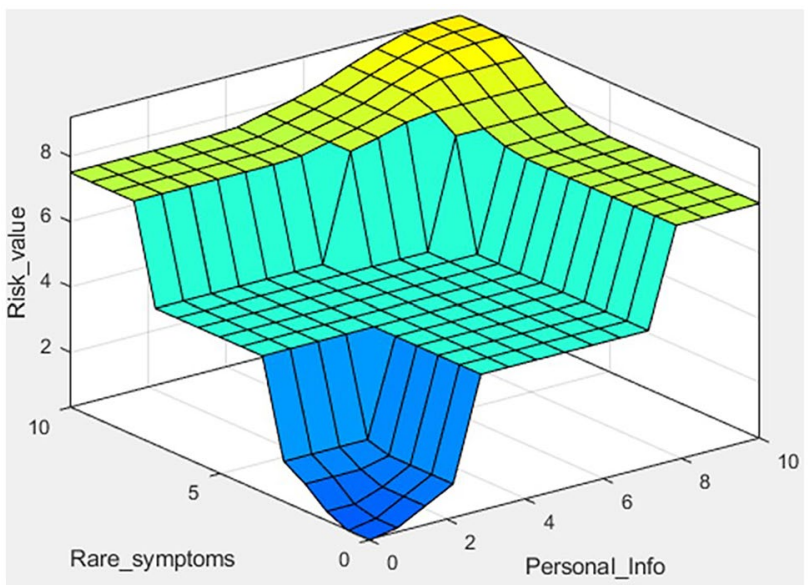

Fig. 15 Rule Base of the Risk Index (Rare Symptoms and Personal Info)

The results show that Person- 1 should take the COVID19 test and must quarantine herself/himself. Person-2 should be careful and don't need to take the test. As a result, the proposed system has a reasonable potential and usefulness and its performance is justified.

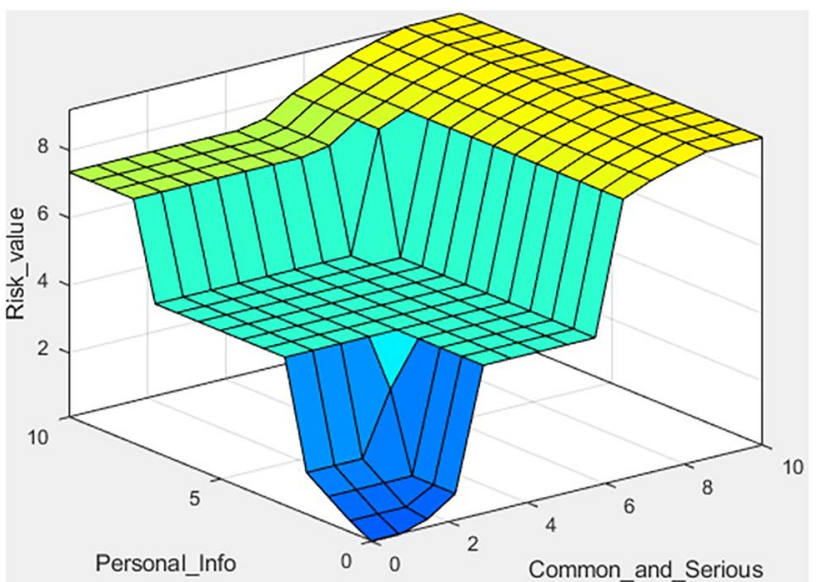

Fig. 16 Rule Base of the Risk Index (Common,-Serious and Personal Info)

\section{Discussion and conclusion}

In this paper, a fuzzy logic inference system was proposed to get a numerical output on COVID-19 symptoms disease so that more specific data is obtained before testing for COVID-19. The data aimed to be obtained with the fuzzy inference system created in the study helps the segregation of individuals at risk of COVID-19 from the society. The data are obtained by evaluating the severity of symptoms mapped on Likert scale $0-10$. The proposed approach has three sub-fuzzy inference system; namely, Common and Serious Symptoms, Rare Symptoms and Personal Information. In the last step, the data obtained from the sub-fuzzy inference systems are used for determinig the personal risk index by means of the final inference system.

The resulting numerical data can be used by health professionals and epidemiologists to make inferences about public health. Numerical output can also be useful in terms of self-control of an individual to help him/her make decisions about seeking appropriate medical care such as Centers for Disease Control and Preventation, 2021, [52]; Columbia University 2021, [53]; and John Hopkins Medicine 2021, [54]. In other words, the proposed approach can
Table 10 Input Data of Two People

\begin{tabular}{llllllll}
\hline FIS type & First FIS & & & & & \\
\hline Inputs & Fever-T & Cough-T & Fatigue-T & Short.of $B$. & CP/Dys. & & \\
Person-1 & $38.2-8$ & $8-7$ & $6-4$ & 1 & No & & \\
Person-2 & $36.5-36$ & $3-18$ & $4-10$ & 0 & No & & \\
FIS type & Second FIS & & & & Third FIS & & \\
Inputs & Loss of $T / S$ & Body-A. & Con. & N/V/D & Age & Smoke & Com. \\
Person-1 & 5 & 7 & No & No & 60 & Yes & No \\
Person-2 & 2 & 6 & No & Yes & 33 & No & Yes (One) \\
\hline
\end{tabular}


Table 11 COVID-19 Risk Index Results for Two People with Input Data in Table 10

\begin{tabular}{lllll}
\hline & First FIS & Second FIS & Third FIS & Final FIS \\
\hline Person-1 & 9.15 & 8.9 & 9.15 & $\mathbf{9 . 2}$ \\
Person-2 & 4.5 & 5 & 4.5 & $\mathbf{4 . 5}$ \\
\hline
\end{tabular}

be a COVID-19 Self-Checker, which is a tool to help make decisions on when to seek testing and appropriate medical care. According to experts' opinions and new studies, improvements and updates can be practically made on the rule base and inputs, as well. On the other hand, this study may be used by epidemiologists for different types of diseases and outbreaks by updating the inputs and rule base. A mobile or digital application of this study can easily be formed in digital health including digital care programs like Health Pass, HES (Life Fits Home Application) in Turkey, which is the convergence of digital technologies with health, healthcare, living, and society to improve the efficiency of healthcare delivery to make medicine more personalized and precise.

Nandal et al. [55] proposed a deep learning framework for Covid-19 detection by using chest X-ray images by first enhancing the image by using fuzzy logic which improvises the pixel intensity and suppresses background noise. In addition, Al-ali et al. [22] implemented an (Adaptive Neuro-Fuzzy Inference System) ANFIS-Net based binary classification process for automatically detecting COVID19 infection from chest X-ray images. Classifier outputs of these systems can also be used as an input- 4 of our approach in the final system by refering to an X-ray image value in order to obtain more advanced and improved result for experts and physicians. This satisfies an evaluation that considers the symptoms and X-ray images together. On the other hand, in the studies [56] and [57], a novel automatic cough frequency monitoring system combining a triaxial accelerator and a stretchable strain sensor AND the development of a machine learning-based analysis framework to connect multimodal wearable sensor data are presented for the cough and fatigue respectively. Based on these researches, we can obtain more measured and improved responses for the severity of fatigue and cough especially in the first FIS. Similary, smell-odor sensors and other techonological devices corresponding to the other inputs can be used to obtain more real and numerical results and to improve the efficiency of the proposed fuzzy approach.

Govindan et al. [28] proposed a similar decision support system based on physicians' knowledge and fuzzy inference system by considering the time as an input value for the most common symptoms. Also, users were divided into subgroups with respect to age and chronic disease. In our system, we consider other symptoms of COVID19 and the severity of the symptoms in addition to the time of most common symptoms in the first FIS. Shatnawi et al. [21] represent a single FIS including the symptoms of COVID-19 that have two membership functions and this system does not include age, chronic disease and smoke. Also, constructing and updating a rule base are more difficult for such system having more inputs. However, the proposed system represents a practical and updatable fuzzy approach. On the other hand, we can also consider other important preventive, inhibiting factors and concepts affecting the spread of COVID-19 like immune response, mask use, social distance, nanoparticles, environmental factors and so on. Then, we can construct a final protection index system from COVID-19 pandemic using these factors and following similar structures. We can see some of the researches investigating such factors in [29, 58-60]. Abstract mathematical and statistical approaches, which can be seen some studies in [61, 62], are another important ways for fighting COVID-19, as well.

In this paper, three membership functions have been considered for input variables where it is possible to promote the accuracy of the proposed system by increasing the number of membership functions. Another limitation is that some of the answers given by users to the questions mentioned in the Section 3.4 may not be absolutely correct.

\section{Summary Points}

What is already known on the topic?

- Reliable and comparable information on the symptoms of COVID19 virus is important.

- Since linguistic concepts and variables are handled by physicians in deciding the diagnosis

and prognosis, the medical area has a great compatibility with fuzzy logic technology and

fuzzy logic is used in the medical decision-making process.

What this study added to our knowledge?

- A decision support system in fuzzy environment is being developed. This system consists

of three sub fuzzy inference systems, Common-Serious symptoms, Rare Symptoms and

Personal Information, and one main system combining the subsystems.

- COVID-19 personal risk index of an individual is obtained by running the proposed infe-

rence system.

- Results obtained from each subsystem and main system can assist healthcare professionals

in a more detailed assesment of symptoms. 
Funding No funding was received to assist with the preparation of this manuscript.

\section{Declarations}

Ethical approval Ethical approval or formal consent is not required for this manuscript.

Conflict of interest The authors declare that they have no conflict of interest.

\section{References}

1. WHO. Listings of WHO's response to COVID-19. $2021 \mathrm{a}$. Retrieved from https://www.who.int/news/item/29-06-2020covidtimeline.

2. WHO. Coronavirus disease (COVID-19) outbreak situation. 2021b. Retrieved from https://covid19.who.int.

3. WHO. The symptoms of COVID-19. 2021c. https://www.who. int/emergencies/diseases/novel-coronavirus-2019/question-andanswers-hub/q-a-detail/coronavirus-disease-covid-19\#:126:text= symptoms.

4. Nannoni S, Groot R, Bell S, Markus HS. Stroke in COVID19: A systematic review and meta-analysis. Int J Stroke. 2020;2020:1-13.

5. Sole FD, Farcomeni A, Loffredo L, Carnevale R, Menichelli D, et al. Features of severe COVID-19: A systematic review and meta-analysis. Eur J Clin Invest. 2020;50.

6. Wong CKH, Wong JYH, Tang EHM, Au, Wai AKC. Clinical presentations, laboratory and radiological findings, and treatments for 11,028 COVID-19 patients: a systematic review and metaanalysis. Sci Rep. 2020;10:19765.

7. Hoang T. Characteristics of COVID-19 recurrence: a systematic review and meta-analysis. 2020. medRxiv, https://doi.org/10. 1101/2020.09.05.20189134.

8. Klopfenstein T, Kadiane-Oussoua NJ, Tokoa L, Royera PY, et al. Features of anosmia in COVID-19. Med Mal Infect. 2020;50:436-9.

9. Burki T. Understanding variants of SARS-CoV-2. The Lancet. 2021;397:10273. https://doi.org/10.1016/S0140-6736(21) 00298-1.

10. Lai S, Floyd J, Tatem A. Preliminary risk analysis of the spread of new COVID-19 variants from the UK, South Africa and Brazil, WorldPop 2021. School of Geopraphy and Environmantel Science: University of Southampton, UK; 2021.

11. WHO. SARS-CoV-2 Variants. 2021d. Online, https://www.who. int/csr/don/31-december-2020-sars-cov2-variants/en/

12. Rao S, Phil D, Singh M. An Evolving Public Health Crisis Caused by the Rapid Spread of the SARS-CoV-2 Delta Variant: The Protective Effect of Vaccination. DHR Proceedings. 2021;1(S4):6-8. https://doi.org/10.47488/dhrp.v1iS4.20.

13. Yang J, Zheng Y, Gou X, Pu K, Chen Z, et al. Prevalence of comorbidities in the novel Wuhan coronavirus (COVID-19) infection: a systematic review and meta-analysis. Int J Infect Dis. 2020;94:91-5.

14. Emami A, Javanmardi F, Pirbonyeh N, Akbari A. Prevalence of underlying diseases in hospitalized patients with COVID-19: a systematic review and meta-analysis. Archives of academic emergency medicine. 2020;8(1).

15. Elliott J, Whitaker M, Bodinier B, Eales O, Riley S, et al. Predictive symptoms for COVID-19 in the community: REACT-1 study of over 1 million people PLoS Med. 2021;18(9): e1003777.
16. Lalka N. Fuzzy Logic for Medical Diagnosis. Master Thesis in Computer Science and Engineering Department, Thapar University, India. 2015.

17. Zadeh LA. Is there a need for fuzzy logic? Inf Sci. 2008;178(13):2751-79.

18. Singla J, Kaur B, Prashar D, Jha S, Joshi GP. A Novel Fuzzy Logic-Based Medical Expert System for Diagnosis of Chronic Kidney Disease. Mob Inf Syst. 2020;2020:8887627.

19. Awotunde JB, Matiluko OE, Fatai OW. Medical Diagnosis System Using Fuzzy Logic. African J Comp ICT. 2014;7(2):99-106.

20. Shaban WM, Rabie AH, Saleh AI, Abo-Elsoud MA. Detecting COVID-19 patients based on fuzzy inference engine and Deep Neural Network. Appl Soft Comp J. 2021;99.

21. Shatnawi M, AlShara Z, Shatnawi A, Husari G. Symptoms-based Fuzzy-Logic Approach for COVID-19 Diagnosis. Int J Adv Comp Sci Appl. 2021;12(4).

22. Al-ali A, Elharrouss O, Qidwai U, Al-Maaddeed S. ANFIS-Net for automatic detection of COVID-19. Sci Rep. 2021;11:17318.

23. Medeirosa IB, Machadoa MAS, Damasceno WJ, Caldeira AM, Santos RC, et al. A Fuzzy Inference System to Support Medical Diagnosis in Real Time. Proc Comp Sci. 2017;122:167-73.

24. Jindal N, Singla J, Kaur B, Sadawarti H, Prasharv D. Fuzzy Logic Systems for Diagnosis of Renal Cancer. Appl Sci. 2020;10:3464.

25. Alkholy EN, Aboutabl AE, Haggag MH. A Proposed Fuzzy Model for Diseases Diagnosis. Int J Eng Adv Tech. 2020;9(3).

26. Sikchi SS, Sikchi S, Ali MS. Fuzzy Expert Systems (FES) for Medical Diagnosis. Int J Comp Appl. 2013;63(11).

27. Ylenia C, Chiara DL, Giovanni I, Lucia R, Donatella V, et al. A Clinical Decision Support System based on fuzzy rules and classification algorithms for monitoring the physiological parameters of type-2 diabetic patients. Math Biosci Eng. 2021;18(3):2654-74.

28. Govindan K, Mina H, Alavi B. A decision support system for demand management in healthcare supply chains considering the epidemic outbreaks: A case study of coronavirus disease 2019 (COVID-19). Transportation Research Part E: Logistics and Transportation Review. 2020;138.

29. Mangla M, Sharma N, Mittala P. Fuzzy Expert System for predicting the Mortality of COVID'19. Turk J Elec Eng and Comp Sci. 2021;29:1628-42.

30. Hamedan F, Orooji A, Sanadgol H, Sheikhtaheri A. Clinical decision support system to predict chronic kidney disease: A fuzzy expert system approach. Int J Med Informatics. 2020;138.

31. Al-Qaness MAA, Ewees AA, Fan H, El Aziz M. Optimization Method for Forecasting Confirmed Cases of COVID-19 in China. J Clin Med. 2020;9:674.

32. Bouncenna N, Bouharati K, Bouharati I, Hamdi-Cherif M. Aggravating and progression factors of COVID-19: Intelligent analysis. Euro Med J, 2021;2:(2).

33. Chowdhury MA, Shah QZ, Kashem MA, Shahid A, Akhtar N . Evaluation of the Effect of Environmental Parameters on the Spread of COVID-19: A Fuzzy Logic Approach. Advances in Fuzzy Systems. 2020;1-5.

34. Fu YL, Liang KC . Fuzzy logic programming and adaptable design of medical products for the COVID-19 antiepidemic normalization. Computer Methods and Programs in Biomedicine. 2020;197:105762.

35. Gemmar P. Mortality Prediction for COVID-19 Patients: Methods and Potential. Journal of Bacteriology \& Parasitology. 2020;11(4).

36. Painuli D, Mishra D, Bhardwaj S, Aggarwal M. Fuzzy Rule Based System to predict COVID19 - A Deadly Virus. Int J Healthcare Manag. 2020;4(8).

37. Shaban WM, Rabie AH, Saleh AI, Abo-Elsoud MA. Detecting COVID-19 Patients Based on Fuzzy Inference Engine and Deep Neural Network. Appl Soft Comput. 2020. https://doi.org/10. 1016/j.asoc.2020.106906. 
38. Chowdhury AA, Hasan KT, Kubra K, Hoque S. Analysis and Prediction of COVID-19 Pandemic in Bangladesh by using Long short-term memory network (LSTM) and Adaptive neuro fuzzy inference system (ANFIS). Cogn Comput. 2020. https://doi.org/ 10.21203/rs.3.rs-55617/v1.

39. Castillo O, Melin P. Forecasting of COVID-19 time series for countries in the world based on a hybrid approach combining the fractal dimension and fuzzy logic. Chaos, Solitons Fractals. 2020;140.

40. Ardabili SF, Mosavi A, Ghamisi P, Ferdinand F, Varkonyi KAR, et al. COVID-19 Outbreak Prediction with Machine Learning. Algorithms. 2020;13:249.

41. Sharma MK, Dhiman N, Vandana Mishra VN. Mediative fuzzy logic mathematical model: A contradictory management prediction in COVID-19 pandemic. Appl Soft Comput. 2021;105.

42. Mamdani EH, Assilian S. An Experiment in Linguistic Synthesis with a Fuzzy Logic Controller. Int J Man-Machine Studies. $1975 ; 7: 1-13$

43. Zimmermann HJ. Fuzzy Set Theory and Its Applications. 3rd ed. Boston/Dordreht/London: Kluwer Academic Publishers; 1996.

44. Sivanandam SN, Sumathi S, Deepa SN. Introduction to Fuzzy Logic using MATLAB. Berlin Heidelberg: Springer-Verlag; 2007.

45. Ross TJ. Fuzzy Logic with Engineering Applications, Third Edition. John Wiley \& Sons Ltd. 2010.

46. Billah A, Miah M, Khan N. Reproductive number of coronavirus: A systematic review and meta-analysis based on global level evidence. PLoS ONE. 2020;15(11).

47. Shmerling RH. Which test is best for COVID-19?. Harvard Health Publishing. 2020. https://www.health.harvard.edu/blog/which-testis-best-for-covid-19-2020081020734\#:126:text=A\%20molecular\% 20test\%20using\%20a,other\%20types\%20of\%20samples\%20taken.

48. Dinnes J, Deeks JJ, Berhane S, Taylor M, Adriano A et al (2020). Rapid, point-of-care antigen and molecular-based tests for diagnosis of SARS-CoV-2 infection. Cochrane Database of Systematic Reviews, Issue 8. Art. No.: CD013705. https://doi.org/10.1002/ 14651858.CD013705.

49. Parekh V, Shah D, Shah M. Fatigue Detection Using Artificial Intelligence Framework. Augmented Human Research. 2020;5(5):1-17.

50. Mullol J, M-Sanchez F, Valls M, Alobid I, Marin C. The sense of smell in chronic rhinosinusitis. J Allergy Clin Immunol 2020;145:773-6.
51. Fontana GA, Widdicombe J. What is cough and what should be measured? Pulmonary Pharmacology \& Therapeutics. 2007;20(4):307-12.

52. Centers for Disease Control and Preventation. 2021. Online, https://www.cdc.gov/coronavirus/2019-ncov/symptoms-testing/ coronavirus-self-checker.html.

53. Columbia University in the City of New York. Online, COVID-19 Resource Guide for Columbia Community COLUMBIA. 2021. https://covid19.columbia.edu/content/symptom-self-checking.

54. John Hopkins Medicine. 2021. Online, https://www.hopkinsmedicine. org/coronavirus/covid-19-self-checker.html.

55. Nandal A, Blagojevic M, Milosevic D, Dhaka A, Mishra LN. Fuzzy enhancement and deep hash layer based neural network to detect Covid-19. J Int Fuzz Syst. 2021:1-11. https://doi.org/10. 3233/JIFS-210222.

56. Otoshi T, Nagano T, Izumi S, Hazama D, Katsurada N, et al. A novel automatic cough frequency monitoring system combining a triaxial accelerometer and a stretchable strain sensor. Sci Rep. 2021;11:9973.

57. Luo H, Lee PA, Clay L, Jaggi M, Luca VD. Assessment of Fatigue Using Wearable Sensors: A Pilot Study. Digital Biomark. 2020;4(suppl 1):59-72.

58. Chowdhury MA, Hossain N, Kashem MA, Shahid A, Alam A. Immune response in COVID-19: A review. J Infect Public Health. 2020;13:1619-29.

59. Chowdhury MA, Shuvho BA, Shahid A, Haque AKMM, Kashem MA, et al. Prospect of biobased antiviral face mask to limit the coronavirus outbreak. Environ Res. 2021;192.

60. Chowdhury MA, Hossain N, Kashem MA, Shahid A, Alam A. Effects of Nanoparticles on Viral Infection-A Review, NANO, 15:09, 2030003.

61. Nath BJ, Dehingia K, Mishra VN, Chu YM, Sarmah HK. Mathematical Analysis of a Within-host Model of SARS-CoV-2. Adv Diff Equ. 2021:113. https://doi.org/10.1186/s13662-021-03276-1.

62. Verma H, Mishra VN, Mathur P. Effectiveness of Lock down to curtail the Spread of Corona Virus: A Mathematical Model. ISA Trans. 2021. https://doi.org/10.1016/j.isatra.2021.01.033.

Publisher's Note Springer Nature remains neutral with regard to jurisdictional claims in published maps and institutional affiliations. 